\title{
Michael Nietsch
}

\section{Freigabeverfahren}

\author{
Beschlusskontrolle bei Strukturveränderungen
}

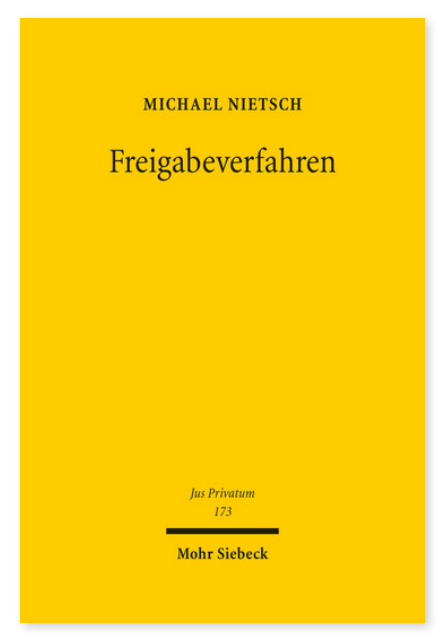

2013. XLIV, 583 Seiten. JusPriv 173

ISBN 978-3-16-152303-8

DOI 10.1628/978-3-16-152303-8

eBook PDF $159,00 €$

ISBN 978-3-16-152203-1

Leinen $159,00 €$
Die Einführung der §§ 16 III UmwG, 246a, 319 VI, 327e II AktG hat dazu geführt, dass sich die Beschlusskontrolle bei wichtigen Strukturänderungen in zunehmendem Maße vom ordentlichen Verfahren in das sog. »Freigabeverfahren « verlagert. Michael Nietsch untersucht die Voraussetzungen und Wirkungen dieses Verfahrens und fragt nach dessen Auswirkungen auf das System der Beschlusskontrolle in seiner Gesamtheit. Lässt sich einerseits feststellen, dass man dem Problem der »räuberischen Anfechtungsklagen« durch das Freigabeverfahren zuletzt besser Herr wird, so sind die damit verbundenen Konsequenzen für die verbandsrechtliche Beschlusskontrolle doch erheblich: Die Entscheidung findet in einem summarischen Verfahren statt. Die gerügten Beschlussmängel bleiben mitunter weitgehend außer Acht, und der Beschluss schafft durch die mit ihm verbundene Bestandsschutzwirkung praktisch vollendete Tatsachen. Michael Nietsch ordnet das Freigabeverfahren in die Dogmatik des Beschlussmangelrechts ein und fragt nach der Vereinbarkeit beider Verfahren. Unter Berücksichtigung verfahrensrechtlicher und verfassungsrechtlicher Grundsätze spricht er sich dabei für ein Verständnis des Freigabeverfahrens als materiell-akzessorisches Eilverfahren aus.

Michael Nietsch Keine aktuellen Daten verfügbar.

Jetzt bestellen:

https://mohrsiebeck.com/buch/freigabeverfahren-9783161523038?no_cache=1

order@mohrsiebeck.com

Telefon: +49 (0)7071-923-17

Telefax: +49 (0)7071-51104 